\title{
Hyperlipoproteinemia and Cerebral Strokes
}

\author{
ANATOLE S. DEKABAN, JAN K. STEUSING AND HAROLD STEVENS
}

\begin{abstract}
Determination of lipoprotein patterns and of major plasma lipids was carried out in 171 patients with strokes. Of these, 22 had hyperlipoproteinemia (HLIPR) by paper electrophoresis and by elevation of principal plasma lipids (either cholesterol over 300 $\mathrm{mg} / 100 \mathrm{ml}$ or triglycerides over 200 $\mathrm{mg} / 100 \mathrm{ml}$ or both these components). More than two-thirds of the patients had at least one close relative with elevated blood lipids. Using criteria of the World Health Organization, these patients were classified as follows: 5 had HLIPR
\end{abstract}

RÉSUMÉ: La détermination des types lipoprotéiniques et des lipides plasmatiques principaux est rapportée chez 171 patients avec accident cérébrovasculaire $(A C V)$. Des deux-ci, 22 souffraient d'hyperlipoprotéinémie (HLIPR) tel que jugé par électrophorèse et par élévation des principaux lipides plasmatiques (soit le cholestérol audessus de $300 \mathrm{mg} / 100 \mathrm{ml}$ ou les triglycérides au-dessus de $200 \mathrm{mg} / \mathrm{ml}$, ou les deux). Plus des deux tiers des patients avaient au moins un proche parent avec une élévation des lipides sanguins. Utilisant les critères de l'Organisation Mondiale de la Santé, ces patients étaient classés comme suit: 5 avaient type IIa, 8 had HLIPR type IIb, 3 had HLIPR type III and 6 had HLIPR type $I V$. Phospholipids showed relatively little change from the values of normal controls. The numerical distribution of patients with stroke and HLIPR into the four different types corresponds quite well with the approximate frequency of these types of HLIPR in the general population. Thus, this study does not indicate that the patients with a particular type of HLIPR are at a greater risk to have a stroke than those belonging to other types.

HLIPR de type IIa, 8 avaient HLIPR de type IIb, 3 avaient HLIPR de type III et 6 avaient HLIPR de type IV. Les phospholipides montraient relativement peu de changements par rapport aux valeurs chez des contrôles normaux. La distribution numérique de patients avec $A C V$ et HLIPR dans les quatre différents groupes correspond très bien avec la fréquence approximative de ces types de HLIPR dans la population en général. Donc, cette étude n'indique pas que les patients avec un type particulier de HLIPR sont plus susceptibles d'avoir un $A C V$ que ceux appartenant aux autres types.

\section{INTRODUCTION}

There is a considerable body of evidence indicating positive association between elevated plasma lipids and atherosclerosis (Cornfield 1962, Brown 1969, Roberto et al., 1973) and also between atherosclerosis and coronary heart disease (Gordon and Kannel, 1972; Brown and Goldstein, 1975). In contrast, the available information on the possible association of strokes and elevated plasma lipids is relatively scarce (deGennes et al., 1968; Gordon et al., 1971; Ballantyne et al., 1974; Gertler, 1975). Recently, limited epidemiological studies on the incidence of strokes in type II hyperlipoproteinemia (HLIPR) has been initiated by the National Heart and Lung Institute. In this communication, we are presenting results of plasma lipoproteins and lipid studies in the patients with stroke who were referred to us for further investigation. Twenty two out of 171 patients with strokes had abnormal lipoprotein patterns and elevated plasma lipids. The pertinent lipid findings were used to classify these patients into various types of hyperlipoproteinemia. In addition to determination of major lipid components, quantitative assessment of partitioned phospholipids was carried out.

\section{PATIENTS AND METHODS}

The 171 patients with recent or past stroke were referred to us by medical practitioners or hospitals in the Washington-Baltimore area. All patients had general and neurological examinations and the essential laboratory work-up which included urinalysis, hemogram, fasting blood glucose, BUN, uric acid and thyroid tests. Using criteria established by the World Health Organization (W.H.O. 1972), presence of charac-
From the Developmental and Metabolic Neurology Branch, National Institute of Neurological and Communicative Disorders and Stroke, National Institutes of Health, Bethesda, Maryland; Department of Neurology, George Washington University Medical School, Washington, D.C.

Reprint requests to Dr. A. S. Dekaban, Dept. of Health, Education and Welfare, Public Health Services National Institutes of Health; Bldg. 10, Room 4N-248; Bethesda Maryland 20014. U.S.A. 
teristic lipoprotein patterns and elevation of total cholesterol (above 300 $\mathrm{mg} / 100 \mathrm{ml}$ ) or triglycerides (above $200 \mathrm{mg} / 100 \mathrm{ml}$ ) or both these components, 22 of the patients with stroke proved to have HLIPR and they are the subject of this study. Patients with diabetes mellitus, gout, alcoholism, thyroid or renal disease were not included.

Eight $\mathrm{ml}$. of freshly drawn blood was added to the test tube containing $8 \mathrm{mg}$. of EDTA (ethylenediaminetetraacetate), mixed, immediately placed on ice and centrifuged. The collected plasma was kept under refrigeration $\left(4^{\circ} \mathrm{C}\right)$ and read next morning for chylomicrons and opalescence against the known standard; subsequently, the plasma was divided into two small test tubes, stoppered and kept at $4^{\circ} \mathrm{C}$ until analyzed. The determination of lipoproteins was done within 2-5 days according to the method of Lees and Hatch (1963). The total cholesterol (TC) was determined by the method of Zak et al. (1954) and Rosenthal et al. (1957), triglycerides (TG) by the enzymatic method of Garland and Randle (1962) and Pinter et al. (1967) phospholipids (PL) by the method of Dryer et al. (1957). The quantitative composition of phospholipids was done using the thin layer chromatography method of Skipski et al. (1964). All determinations were carried out in duplicate.

\section{RESULTS}

Out of 22 patients with strokes and HLIPR, 17 were males and 5 females. The marked preponderance of males probably reflects a substantial referral of patients from the local VA or military hospitals. The mean age of these patients when blood for lipids was drawn was 56.2 with the range of 28 to 71 years. Nine patients had only one stroke or a transient ischemic attack ( 2 patients) and 13 had multiple cerebrovascular events. Five patients had their first or repeated stroke within 6 weeks of drawing blood for this study. In addition to an atherothrombotic cerebral condition, eleven patients had evidence of coronary heart disease but only one had xanthoma
TABLE 1

PLASMA LIPIDS $(\mathrm{mg} / 100 \mathrm{ml})$ AND LIPOPROTEIN PATTERNS

IN SIX NORMAL CONTROLS, MEAN AGE 50.2 YEARS

\begin{tabular}{|c|c|c|c|c|c|}
\hline CASE & NO./SEX/AC & $\mathrm{TC}$ & $T G$ & $P L$ & LP PATTERNS \\
\hline 1. & $M / 54 y$ & 195 & 61 & 206 & Normal \\
\hline 2. & $F / 40 y$ & 250 & 103 & 220 & Normal \\
\hline 3. & $M / 61 y$ & 260 & 162 & 259 & Normal \\
\hline 4. & $M / 33 y$ & 206 & 88 & 203 & Normal \\
\hline 5. & $F / 55 y$ & 277 & 132 & 316 & Norma 1 \\
\hline 6. & $M / 58 y$ & 245 & 102 & 240 & Normal \\
\hline MEANS & $S \pm S E M$ & $238.8 \pm 13.1$ & $108.0 \pm 14.4$ & $240.6 \pm 17.4$ & \\
\hline $\begin{array}{l}\text { MEANS } \\
\text { FRED } \\
\text { LEVY }\end{array}$ & $\begin{array}{l}S \text { OF * } \\
\text { RICKSON \& }\end{array}$ & 235 & 90 & --- & \\
\hline
\end{tabular}

*FREDRICKSON AND LEVY (1972); THE VALUES OF THEIR AGE GROUPS 40-49 AND 50-59 YEARS WERE COMBINED.

TC - TOTAL CHOLESTEROL; TG - TOTAL TRIGLYCERIDES: PL - PHOSPHOLIPIDS;

LP - LIPOPROTEINS.

$\underline{\text { TABLE } 2}$

PLASMA LIPIDS (mg/100m l) AND LIPOPROTEIN PATTERN IN PATIENTS WITH

TYPE II A HYPERLIPOPROTEINEMIA WHO SUFFERED STROKE;MEAN AGE 50.4 YEARS

\begin{tabular}{|c|c|c|c|c|c|}
\hline CASE & NO./SEX/AGE & TC & $\mathrm{TG}$ & $\mathrm{PL}$ & LP PATTERN \\
\hline 1. & $\mathrm{~F} / 60 \mathrm{y}$ & 338 & 81 & 291 & Beta ${ }^{+}$ \\
\hline 2. & $F / 28 y$ & 408 & 130 & 310 & Beta $\uparrow \uparrow$ \\
\hline 3. & $M / 70 y$ & 322 & 216 & 243 & Beta $\uparrow$ \\
\hline 4. & $M / 62 y$ & 301 & 99 & 305 & Beta $\uparrow$ \\
\hline 5. & $M / 32 y$ & 304 & 129 & 223 & Beta $\uparrow$ \\
\hline MEANS & $S \pm S E M$ & $334.6 \pm 19.5$ & $131.0 \pm 23.2$ & $288.40 \pm 18.7$ & \\
\hline
\end{tabular}

\footnotetext{
TC - TOTAL CHOLESTEROL; TG - TRIGLYCERIDES; PL - PHOSPHOLIPIDS;

LP - LIPOPROTEINS

$\uparrow$ - Substantially Elevated; $\uparrow \uparrow$ - MARKEDly Elevated
} 
TABLE 3

PLASMA LIPIDS (mg/100ml) ANंD LIPOPROTEIN PATTERN IN PATIENTS WITH

TYPE IIb HYPERLIPOPROTEINEMIA WHO SUFFERED STROKE; MEAN AGE 59.4 YEARS

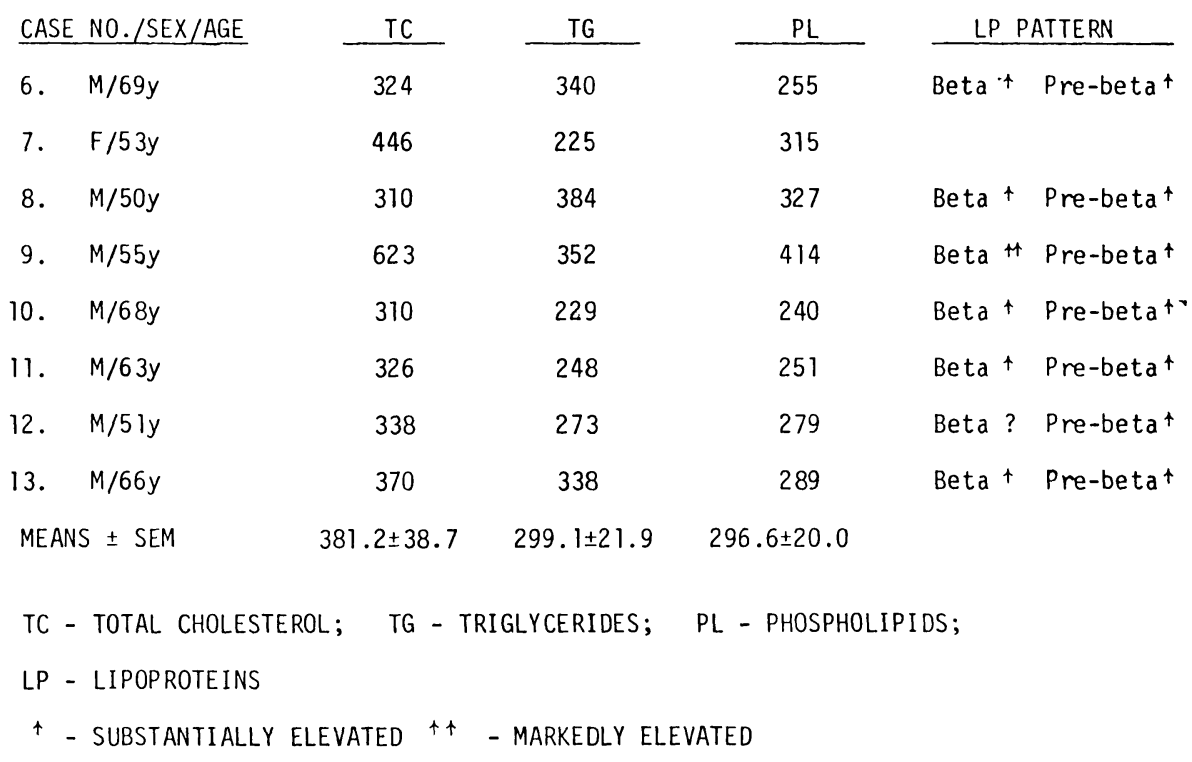

tuberosum. Of the 17 patients who were ambulatory 8 were able to perform part time work or some work around the house; 5 patients required nursing care -3 of these had hemiplegia 3-14 days prior to drawing blood for lipids. About twothirds of all patients were on a nonstringent voluntary reduction of animal fats and food high in cholesterol.

In order to provide data from the general population for comparison, we have tabulated lipid values of six normal controls in our laboratory (Table 1) and also listed means from a larger series of Fredrickson and Levy (1972). According to the criteria used, all our patients fell into one of the following four types of HLIPR: type IIa, IIb, III and IV. Sixteen of 22 patients had at least one close relative who was known to have high blood lipids.

Table 2 shows results of lipids and lipoproteins in 5 patients with type IIa HLIPR. The beta fraction of lipoproteins was clearly increased and this was associated with elevated TC but essentially normal TG and PL, except of one patient (case 3) whose TG were mildly elevated. Type IIb HLIPR, which is charac-

PL - PHOSPHOLIPIDS; LP - LIPOPROTEINS terized by the elevation of beta and pre-beta fractions, was present in 8 patients with strokes (Table 3). Both TC and TG were substantially elevated with means of 381.2 and 299.0 $\mathrm{mg} / 100 \mathrm{ml}$, respecitvely. The PL were slightly but not significantly higher than in normal controls.

Table 4 shows lipid data in 3 patients with type III HLIPR; they all had broad beta lipoprotein patterns and markedly elevated TG and more than moderately elevated TC, the respective means being 514.7 and $382.2 \mathrm{mg} / 100 \mathrm{ml}$. Also, the mean

TABLE 4

PLASMA LIPIDS $(\mathrm{mg} / 100 \mathrm{ml})$ AND LIPOPROTEIN PATTERN IN PATIENTS WITH

TYPE III HYPERLIPOPROTEINEMIA WHO SUFFERED STROKE; MEAN AGE 58.3 YEARS
CASE NO./SEX/AGE

14. $M / 64 y$

15. $M / 57 y$

16. $M / 54 y$

MEANS \pm SEM

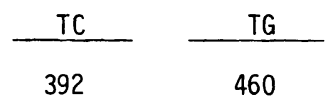

365

388

520

563
$382.2 \pm 8.5$

$514.7 \pm 30.0$

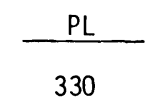

409

307

$348.9 \pm 31.0$
LP PATTERN

Broad beta

Broad beta

Broad beta

TC - TOTAL CHOLESTEROL; TG - TRIGLYCERIDES; * $\mathrm{p}<0.05$; 
these patients were classified as having hyperlipoproteinemia Type IV. However, five of them had also diabetes mellitus and three gout; this greatly complicates the interpretation of the elevated serum lipids and of the lipoprotein patterns. The authors found that platelet coagulant activities which are concerned with the early stages of coagulation, were increased 2-3 times in 12 patients with transient ischemic attacks and normal serum lipids. In contrast, their 10 patients with hyperlipoproteinemia Type IV (according to their judgement) had normal platelet activity. The authors speculated that elevated plasma triglycerides could protect platelets from becoming hyperactive.

\section{DISCUSSION}

No detailed incidence of various types of familial HLIPR in the gen-

\section{TABLE 5}

PLASMA LIPIDS (mg/100ml) AND LIPOPROTEIN PATTERN IN PATIENTS WITH

TYPE IV HYPERLIPOPROTEINEMIA WHO SUFFERED STROKE; MEAN AGE 56.6 YEARS

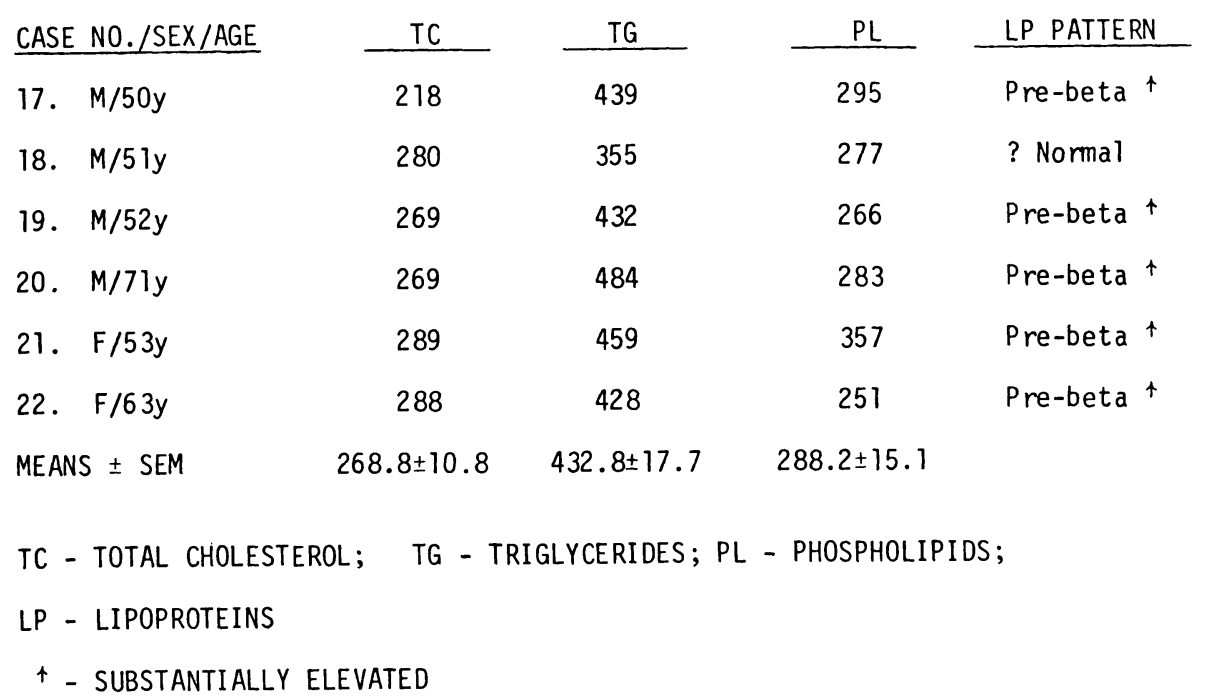

eral population is available, but the information obtained from the Fredrickson and Levy (1972) study suggests the following order in decreasing frequency: HLIPR type II (by far the most common), then type IV, type III, type V and finally type I. In this communication we have placed the main emphasis on recording raw and detailed results of plasma lipids and lipoproteins in patients with strokes and HLIPR. The criteria for patient selection was purposely stringent. In addition to the elevation of certain fractions of lipoproteins, either TC or TG or both these components had to be significantly higher than in the general population (TC above 300 and/or TG above 200 $\mathrm{mg} / 100 \mathrm{ml}$ ). Because of the history of high incidence of elevated blood lipids in the close relatives, most of our patients probably belong to various types of familial hyperlipoproteinemia. For this reason it should be not surprising that the results of this and other investigators' studies differ considerably.

The following are some of the more recent reports on larger series of patients with strokes and associated abnormality of blood lipids. Gertler et al. (1975) considered interrelationship between various risk factors and occurrence of cerebrovascular disease. The means of

TABLE 6

MEANS OF THE COMPOSITION OF PHOSPHOLIPIDS IN VARIOUS TYPES OF HYPERLIPOPROTEINEMIA IN PATIENTS WITH STROKES

\begin{tabular}{|c|c|c|c|c|c|c|c|}
\hline $\begin{array}{l}\text { TYPE OF HYPER- } \\
\text { LIPOPROTEINEMIA }\end{array}$ & $\begin{array}{l}\text { Noi } \\
\text { PT'S }\end{array}$ & $\begin{array}{l}\text { TOTAL PL } \\
\mathrm{mg} / 100 \mathrm{ml}\end{array}$ & SPHINGOM. & $\begin{array}{l}\text { PHOS. } \\
\text { CHOL. }\end{array}$ & $\begin{array}{l}\text { LYSO. } \\
\text { PHOS. } \\
\text { CHOL. }\end{array}$ & $\begin{array}{l}\text { PHOS. } \\
\text { SER. }\end{array}$ & $\begin{array}{l}\text { PHOS. } \\
\text { ETHOL }\end{array}$ \\
\hline LP II ạ & 5 & 274.4 & 9.5 & 54.8 & 22.0 & 5.0 & 9.3 \\
\hline LP IIb & 8 & 302.4 & 11.8 & 51.5 & 20.8 & 5.9 & 9.7 \\
\hline LP II I & 3 & $348.9^{\star}$ & 10.3 & 52.4 & 20.5 & 6.3 & 10.5 \\
\hline LP IV & 6 & 288.7 & 7.6 & $61.2^{*}$ & 17.5 & 5.8 & 7.9 \\
\hline CONTROLS & 6 & 237.0 & 10.4 & 50.7 & 19.6 & 7.8 & 11.6 \\
\hline
\end{tabular}

PL - PHOSPHOLIPIDS; SPHINGOM - SPHINGOMYELIN; PHOS. CHOL. - PHOSPHATIDYL CHOLINE;

LYSO. PHOS. CHOL. - LYSOPHOSPHATIDYL CHOLINE; PHOS. SER. - PHOSPHATIDYL SERINE;

PHOS. ETHOL. - PHOSPHATIDYL ETHANOLAIMINE.

$\star p<0.05$ 
serum triglycerides of their patients were significantly higher $(\mathrm{p}<0.05)$ than in the age-matched controls, but the means of cholesterol and phospholipids were normal. These authors also found a substantial preponderance of type IV lipoproteins. Likewise, Bansal et al. (1975) found a statistically significant rise in serum triglycerides and pre-beta lipoprotein in their patients as a group. Since in neither of these studies lipid data on individual patients are listed, it is not possible to determine the number of patients with HLIPR. Among 163 patients with stroke who had serum lipid and lipoprotein determinations, Mathews et al. (1975) found 52 (31.8\%) with HLIPR. Thirty six of these $(69.2 \%)$ were considered to have type IV, 15 (28.9\%) type II and I (1.9\%) type V HLIPR. The criteria which these authors used were different from ours and the high incidence of HLIPR in their series would have to be considered in this light. The mean serum cholesterol level in patients of all their five subgroups (according to the site of the cerebral arterial lesion) was normal and the mean level of triglycerides was elevated only in their groups $A$ and $B(248 \pm 80$ and $213 \pm$ $75 \mathrm{mg} / 100 \mathrm{ml}$ respectively). No lipids and lipoprotein data on individual patients was given. One of their interesting findings was preponderance of atherosclerotic lesions in the extracranial arteries as demonstrated by angiography. Of greater relevance to our study is the report of French investigators (de Gennes et al., 1968). They described cerebral vascular complications in patients with familial hypercholesteremic tendinous xanthomatosis. Among 107 cases the incidence of patients with permanent brain sequelae was $27 \%$ and this incidence was much higher when transient ischemic attacks and less well defined history of cerebral vascular symptoms were also included.

It is probably a reflection of different criteria used in selecting stroke patients with elevated blood lipids which account for a great variation in the numbers of patients in individual types of HLIPR and for the differences in the overall incidence of strokes in HLIPR. In this study, the numbers of patients with strokes who were classified as type IIa, IIb, III or IV HLIPR corresponded quite well to the approximate order of frequencies of these types of HLIPR in the general population. Therefore, this investigation does not indicate that the patients with a particular type of HLIPR are at a greater risk to have a stroke than those belonging to another type. However, a larger series of patients may be needed to verify and extend these observations.

\section{REFERENCES}

BALLANTYNE, D., GROSSART, K. W G., BALLANTYNE, J. P., YOUNG, A. and LAWRIE, T.D.: (1974) Relationship of plasma lipids and lipoprotein concentration to cerebral atherosclerosis and electroencephalographic findings. J. Neurol. Sci. 23: 323-329.

BANSAL, B. C., GUPTA, R. R. and BANSAL, M. R.: (1975) Serum lipids and uric acid relationship in ischemic thrombotic cerebrovascular disease. Stroke 6: 304-397

BROWN, D. F.: (1969) Blood lipids and lipoproteins in atherogenesis. Am. J. Med. 46: 691-704.

BROWN, M. S. and GOLDSTEIN, J. L.: (1975) Familial hypercholesterolemia: genetic, biochemical and pathophysiological considerations. Adv Int. Med. 20: 273-296.

CORNFIELD, J.: (1962) Joint dependence of risk of coronary heart disease on serum cholesterol and systolic blood pressure: A discriminant function and analysis. Fed. Proc. 21, Part II: 58-61.

de GENNES, J. L., ROUFFY, J. and CHAIN, F.: (1968) Complications vasculaires cerébrales des xanthomatoses tendineuses hypercholestérolémiques familiales. Bull. Soc. Med. Hop. Paris 119: 569-586.

DRYER, R. L., TAMMES, A. R. and ROUTH, J. I.: (1957) The determination of phosphorous and phosphatase with N-phenyl-p-phenylenediamine. J. Biolog. Chem. 225: 177-183.

FREDRICKSON, D. S. and LEVY, R. I.: (1972) Familial hyperlipoproteinemia. In: The Metabolic Basis of Inherited Disease. (ed.) J. B. Stanbury, McGraw-Hill, New York p 545-614.
GARLAND, $P$ E. and RANDLE, P. J.: (1962) A rapid enzymatic assay for glycerol. Nature 196: 987-988.

GERTLER, M. M., LEETMA, H. E., KOUTROUBY, J. and JOHNSON, E. D.: (1975) The assessment of insulin, glucose and lipids in ischemic thrombotic cerebrovascular disease. Stroke 6: 77-84.

GORDON, T., SORLIE, P. and KANNEL, W. B.: (1971) The Framingham Study. An epidemiological investigation of cardiovascular disease. Section 27 Coronary heart disease atherothrombotic brain infarction, intermittent claudication. A multivariant analysis of some factors related to their incidence. Framingham Study, 16-year follow-up. U.S. Dept. of Health, Education and Welfare.

GORDON, T. and KANNEL, W. B.: (1972) Predispostion to atherosclerosis in the head, heart and legs. The Framingham Study J.A.M.A. 221: 661-666.

LEES, R. S. and HATCH, F. T.: (1963) Sharper separation of lipoprotein species by paper electrophoresis in albumin containing buffer J. Lab. and Clin. Med. 61: 518-528.

MATHEWS, N. T., DAVIS, D., MEYER, J. S. and CHANDAR, K. (1975). Hyperlipoproteinemia in occlusive cerebrovascular disease. J.A.M.A. 232: 262-266.

PINTER, J. K., HAYASKI, J. A. and WATSON, J.A.: (1967) Enzymatic assay of glycerol, dihydroxyacetone and glyceraldehyde. Arch. Biochern. Biophys. 121: 404-414.

ROBERTS, W. C., FERRANS, V. J., LEVY, R. I. and FREDRICKSON, D. S.: (1973). Cardiovascular pathology in hyperlipoproteinemia. Anatomic observations in 42 necropsy patients with normal or abnormal serum lipoprotein patterns. Am. J. Cardiol. 31: 557-570.

ROSENTHAL, H. L., PFLUKE, M. L. and BUSCAGLIA, S.: (1957) A stable iron reagent for determination of cholesterol. J. Lab. and Clin. Med. 50: 318-322.

SKIPSKI, V P., PETERSON, R. F and Barkley, M.: (1964) Quantitative analysis of phospholipids by thin layer of chromatography. Boichem. J. 90: 374-378.

WALSH, P. N., PARETI, F. I. and CORBETT, J. J.: Platelet coagulant activities and serum lipids in transient cerebral ischemia. New Engl. J. Med. 295: 854-858, October 1976.

World Health Organization Memorandum: (1972) Classification of hyperlipidemias and hyperlipoproteinemias. Circulation 45: 501-508.

ZAK, B., DICKEMAN, R. C., WHITE, E. G., BURNETT, H. and CHARNEY, P. J.: (1954) Rapid determination of free and total cholesterol. Am. J. Clin. Path. 24: 1307-1315. 